\title{
Comparison of temporary and permanent catheters for acute peritoneal dialysis
}

\author{
S N WONG AND D F GEARY \\ Division of Nephrology, Department of Paediatrics, Hospital For Sick Children, Toronto
}

SUMmARY The records of 64 children who underwent acute peritoneal dialysis in the Hospital for Sick Children, Toronto, between 1 January 1982 and 31 December 1985 were reviewed. Rigid Trocath catheters were used in 33 patients and silastic Tenckhoff catheters in 34 . The groups were comparable for age, weight, primary disease, duration of dialysis, and outcome. There were no significant differences in the incidences of leakage of dialysate, two way obstruction, bleeding, or peritonitis. Among those who had Trocath catheters there were significantly more episodes of outflow obstruction, and significantly more patients required two or more catheter insertions (12 of 33 compared with one of 34 among those who had Tenckhoff catheters). Furthermore, more catheters were removed because of complications ( 19 of 33 compared with five of 34 respectively). One patient who had a Tenckhoff catheter died of peritonitis directly related to insertion of the catheter. Overall, the Tenckhoff catheter was associated with fewer complications and is recommended for most patients.

Peritoneal dialysis in children was first described by Swan and Gordon in $1949 .{ }^{1}$ Since then it has been used successfully for the short term treatment of acute renal failure, ${ }^{2}{ }^{3}$ intoxication states, ${ }^{4}$ and metabolic abnormalities. ${ }^{5}{ }^{6}$ Until recently nephrologists relied on rigid polyethylene catheters placed percutaneously such as the Trocath (McGaw Laboratories) for acute dialysis. In many centres these have now been replaced by the flexible silicone rubber catheter introduced by Tenckhoff and Schechter in $1968,^{7-9}$ which was originally designed for chronic dialysis. Although the Tenckhoff catheter has been associated with infections and mechanical problems,${ }^{10}$ it has many advantages compared with the Trocath catheter. Its softness allows it to be tunnelled subcutaneously in the anterior abdominal wall, and its Dacron cuffs reduce the incidence of complications such as infection, leakage, and accidental dislodgement. The Tenckhoff catheter, however, is expensive and requires an operation to insert it. In children general anaesthesia may be necessary, which delays starting dialysis. Consequently for short term acute treatment the simpler and cheaper Trocath catheter may be a satisfactory alternative. To our knowledge, the two catheters have not been compared for acute peritoneal dialysis. In the present study we reviewed the incidence of complications in acute peritoneal dialy- sis using either the Trocath or the Tenckhoff catheter.

\section{Patients and methods}

The charts of all patients undergoing acute peritoneal dialysis at the Hospital for Sick Children, Toronto, between 1 January 1982 and 31 December 1985 were reviewed. Children with previously recognised chronic renal failure were excluded. Before 1982 all catheters for acute peritoneal dialysis were inserted using the Trocath by the acute stab technique. From 1982 to December 1985 both Trocath and Tenckhoff catheters were used depending on the clinical preference of the responsible physician. In some instances the decision was determined by the patient's clinical condition-for example, surgical placement of a Tenckhoff catheter because of a coagulation disturbance or (rarely) insertion of a Trocath for immediate dialysis because of a life threatening metabolic disturbance such as hyperkalaemia.

Peritoneal dialysis was the treatment of choice and was successfully initiated in all patients. The duration of dialysis was recorded from the date of insertion of the catheter to the date dialysis finished. The duration of acute dialysis was limited to 30 days in all cases. Patients dialysed for longer periods were 
arbitrarily considered to have started chronic dialysis. The techniques used for percutaneous stab followed standard recommendations already reported. ${ }^{9}$ Tenckhoff catheters were surgically placed as previously described. ${ }^{910}$ Heparin or antibiotics were added to the dialysate depending on the individual physician's preference.

All recorded complications were based on the clinical diagnosis of the physicians in charge of the patients. Infections of the exit site or tunnel were diagnosed if redness, swelling, pain, and discharge were seen at the site. Peritonitis was diagnosed when a culture showed bacterial growth in association with one or more of the following: cloudy fluid, leucocytosis in the fluid (white cell count of $>50 \times 10^{9} / 1$ with more than $50 \%$ neutrophils), or bacteria seen on a Gram stained smear. A variety of mechanical complications were recorded. Leakage of dialysate was diagnosed when frequent dressing changes were needed, when there was a decrease in the cycle volumes, or resuturing or removal of the catheter were required. Outflow obstructions were diagnosed if there was slow drainage and persistent positive cycle balance, and they required catheter manipulation, irrigation, or removal. Two way obstruction was indicated by slow inflow and outflow and resistance to irrigation. Intraperitoneal bleeding was recorded if bloodstained dialysate was returned after the first three cycles of exchange. Abdominal pain was recorded as a complication if analgesics were required. The complication rates were calculated for both groups.

Statistical analyses were performed using Student's $t$ test and Fisher's exact test where appropriate. A $p$ value of $<0.05$ was considered significant.

\section{Results}

From 1 January 1982 to 31 December 1985, 75 children were dialysed for acute illnesses and charts were available for review for 64. Thirty three patients were dialysed using the Trocath, and 34 using the Tenckhoff catheter. Three patients had Trocath catheters inserted first but were given Tenckhoff catheters later; they are included in both groups. All Trocath catheters were inserted by stab under local anaesthesia. The location of the catheter was not always recorded. In the group who had Tenckhoff catheters, the catheters were inserted surgically, either under general anaesthesia in the operating theatre, $n=19(56 \%)$ or under local anaesthesia in the intensive care unit, $n=15(44 \%)$. The same surgical technique was used for insertion of all Tenckhoff catheters, and omentectomy was rarely necessary. All children in whom Tenckhoff cath- eters were inserted under local anaesthesia were sedated, and were already being ventilated as part of their overall management. Heparin was used in 21 of 33 patients in the group with Trocath catheters and 23 of 34 patients with Tenckhoff catheters $(p>0.05)$. Prophylactic antibiotics were added to the dialysate in 14 patients with Trocath catheters and 19 patients with Tenckhoff catheters $(p>0 \cdot 05)$.

The mean age was 3.41 years (range 2 days to 15 years) for those with Trocath catheters and 3.41 years (range 1 day to 15 years) for those with Tenckhoff catheters. Mean body weight was $15 \cdot 1 \mathrm{~kg}$ (range 1.3-65.9) in those with Trocath catheters and $12.5 \mathrm{~kg}$ (range $3.3-32.6$ ) in those with Tenckhoff catheters. There were no significant differences between the groups in age and body weight, and both had the same pattern of primary diseases (table 1).

The mechanical complications associated with peritoneal dialysis are shown in table 2 . The most

Table 1 Primary diseases in patients undergoing acute peritoneal dialysis

\begin{tabular}{lll}
\hline & $\begin{array}{l}\text { Group with } \\
\text { Trocath } \\
\text { catheters } \\
(n=33)\end{array}$ & $\begin{array}{l}\text { Group with } \\
\text { Tenckhoff } \\
\text { catheters } \\
(n=34)\end{array}$ \\
\hline $\begin{array}{l}\text { Acute tubular necrosis: } \\
\quad \text { Cardiac operation }\end{array}$ & 6 & 16 \\
$\quad \begin{array}{l}\text { Other causes of shock } \\
\text { Haemolytic uraemic } \\
\text { syndrome }\end{array}$ & 9 & 4 \\
$\begin{array}{l}\text { Poststreptococcal } \\
\text { glomerulonephritis }\end{array}$ & 12 & 10 \\
$\begin{array}{l}\text { Interstitial nephritis } \\
\text { Metabolic abnormalities }\end{array}$ & 1 & 1 \\
$\begin{array}{l}\text { Acute rejection after } \\
\text { transplant }\end{array}$ & 1 & 0 \\
\hline
\end{tabular}

Table 2 Complications of acute peritoneal dialysis

\begin{tabular}{lll}
\hline & $\begin{array}{l}\text { Group with } \\
\text { Trocath } \\
\text { catheters } \\
(n=33)\end{array}$ & $\begin{array}{l}\text { Group with } \\
\text { Tenckhoff } \\
\text { catheters } \\
(n=34) \\
\text { No (\%) }\end{array}$ \\
\hline Leakage of dialysate & $12(36)$ & $10(29)$ \\
Outflow obstruction & $10(30)$ & $2(6)^{*}$ \\
2-way obstruction & $2(6)$ & $1(3)$ \\
Dislodgement of catheters & $3(9)$ & 0 \\
Puncture site bleeding & $1(3)$ & $1(3)$ \\
Intraperitoneal bleeding & $3(9)$ & $5(15) \dagger$ \\
Abdominal pain & $3(9)$ & $2(6)$ \\
Fibrin clots in dialysate & $3(9)$ & $3(9)$ \\
Peritonitis & $5(15) \ddagger$ & $5(15)$
\end{tabular}

*Fisher's exact test, $(p<0 \cdot 01)$; tone patient with haemorrhagic pancreatitis and one with enterocolitis and bloody ascites have been excluded; fone patient in whom peritonitis was presen before dialysis has been excluded. 
common problem in both groups was leakage of dialysate, which occurred in 12 patients with Trocath catheters and 10 with Tenckhoff catheters. The leakage was noted during the first 48 hours after catheter insertion in four of the 12 and two of the 10 , respectively. Management of those with Trocath catheters comprised decreasing the cycle volume alone in four patients, resuturing in two, and removing the catheter in six. In those with Tenckhoff catheters, one patient required resuturing, one required removal of the catheter and the rest had only the cycle volume reduced. Although the difference in leakage rate between the two groups was not significant, the problem of leakage was more serious in those with Trocath catheters. Outflow obstruction was significantly more common in those with Trocath catheters (10 of 33 patients compared with only two of 34 in the other group, $p<0.01)$ and necessitated removal of the catheter in six. In addition, three Trocath catheters accidentally became dislodged. Two catheters slipped out completely, and a third was displaced so that the side holes were outside the peritoneal cavity, causing extravasation of dialysate into the anterior abdominal wall. No such complication occurred in the group with Tenckhoff catheters.

Bloodstained dialysate was seen more often with Tenckhoff catheters than with Trocath catheters (five of 34 compared with three of 33). Two further patients with Tenckhoff catheters bled, from haemorrhagic pancreatitis in one and from enterocolitis with bloody ascites in the other. In the group with Trocath catheters, one patient had severe intraperitoneal bleeding that caused a fall in haemoglobin concentration and required a blood transfusion. All episodes of bleeding subsided spontaneously without either removal of the catheter or laparotomy. Minor complications such as abdominal pain during infusion or draining of dialysate, formation of fibrin clots in the dialysate, or local bleeding from the site of introduction of the catheter, were similar in both groups. Interestingly, two patients with Tenckhoff catheters leaked fluid into the thoracic cavity causing a pleural effusion in one, and leakage of fluid from the chest drains and the thoracotomy wound in the other. Only one of these children is included among the 10 patients with Tenckhoff catheters described above as having leakage of dialysate. The reason for leakage of fluid into the chest, which was only seen in patients with Tenckhoff catheters, was not apparent.

The incidence of infections was similar in both groups. Five patients in each group developed peritonitis. The organisms involved were coliforms in four patients, Pseudomonas spp. in three, Candida albicans in three, Staphylococcus epidermidis in three, Streptococcus pyogenes in two, and Staphylococcus aureus in one. Four patients had peritonitis due to multiple organisms. The time of onset of peritonitis was also similar (nine days in those with Trocath catheters and 10.4 days in those with Tenckhoff catheters, $p>0 \cdot 05$ ). Among those with Trocath catheters, two of the five patients had the same organisms cultured from the blood, whereas in the group with Tenckhoff catheters one patient with peritonitis developed septicaemia caused by the same organism. Infections of the exit sites were uncommon, occurring in only one patient in each group.

The patients with Trocath catheters were dialysed for an average of $7 \cdot 1$ days compared with $9 \cdot 0$ days for those with Tenckhoff catheters (table 3), but this difference was not significant. Twelve patients with Trocath catheters required insertion of two or more catheters during the course of dialysis compared to one in the other group. Altogether 19 patients who were given a Trocath catheter initially had to have their catheters removed while they still needed dialysis because the catheters ceased to function and caused complications; this was necessary in only five patients initially dialysed with Tenckhoff catheters. If all mechanical and infective complications were combined, the chance of a complication occurring during dialysis with the Trocath catheter was 45 episodes in 233 patient days or 0.19 episodes per patient day. The corresponding figures for dialysis with the Tenckhoff catheter were 31 episodes in 304 patient days or $0 \cdot 10$ episodes per patient day of dialysis.

Eighteen patients with Trocath catheters and 15

Table 3 Outcome of patients undergoing acute peritoneal dialysis

\begin{tabular}{|c|c|c|}
\hline & $\begin{array}{l}\text { Group with } \\
\text { Trocath } \\
\text { catheters } \\
(n=33)\end{array}$ & $\begin{array}{l}\text { Group with } \\
\text { Tenckhoff } \\
\text { catheters } \\
(n=34)\end{array}$ \\
\hline \multicolumn{3}{|l|}{ Duration of dialysis: } \\
\hline Total patient days & 233 & 304 \\
\hline mean (range) & $7 \cdot 1(1-15)$ & $9 \cdot 0(1-30)$ \\
\hline \multicolumn{3}{|l|}{$\begin{array}{l}\text { Overall complication rate: } \\
\text { (Episodes per patient }\end{array}$} \\
\hline $\begin{array}{l}\text { Patients for whom } \\
\text { catheter removed } \\
\text { because of }\end{array}$ & 0.19 & \\
\hline complications & 19 & $5^{*}$ \\
\hline $\begin{array}{l}\text { Patients requiring two or } \\
\text { more catheters }\end{array}$ & 12 & $1^{*}$ \\
\hline Complete recovery & 18 & 15 \\
\hline Chronic renal failure & 3 & 5 \\
\hline Death & 12 & 14 \\
\hline
\end{tabular}

${ }^{*}$ Fisher's exact test, $\mathrm{p}<0.001$. 
Table 4 Causes of death in patients undergoing acute peritoneal dialysis

\begin{tabular}{lll}
\hline & $\begin{array}{l}\text { Group with } \\
\text { Trocath } \\
\text { catheters }\end{array}$ & $\begin{array}{l}\text { Group with } \\
\text { Tenckhoff } \\
\text { catheters }\end{array}$ \\
\hline Cardiac failure & 4 & 9 \\
Multiorgan failure & 5 & 2 \\
Cerebral infarction & 0 & 1 \\
Metabolic abnormalities & 3 & 1 \\
Catheter related peritonitis & 0 & 1 \\
\hline
\end{tabular}

with Tenckhoff catheters achieved complete renal recovery and survived. Three and five, respectively, were stabilised by peritoneal dialysis but had persistent chronic renal failure that required continuous ambulatory peritoneal dialysis. Twelve patients with Trocath catheters and 14 with Tenckhoff catheters died despite peritoneal dialysis. With one exception, the cause of death was not related to dialysis (table 4). The only catheter related death was from peritonitis, and this occurred in the group with Tenckhoff catheters.

\section{Discussion}

The incidence of complications in our patients dialysed with the Trocath catheter was comparable with experience elsewhere. In a series of 184 dialyses in children and adults, Vaamonde et al reported leakage of dialysate in $36 \%$ of patients, inadequate drainage in $37.5 \%$, intra-abdominal bleeding in $32 \%$, and peritonitis in $6.3 \% .{ }^{11}$ Valk et al reported that $14 \%$ of their adult patients having acute peritoneal dialysis had leakage of dialysate, $39 \%$ had inadequate drainage, $30 \%$ had bleeding, and $3 \%$ had peritonitis. ${ }^{12}$ Rigden et al reported severe bleeding in $4 \%$, and peritonitis in $16 \%$, of the 24 children in their series who underwent acute peritoneal dialysis after cardiopulmonary bypass operations. ${ }^{13}$

We achieved a significant reduction in outflow obstruction with the Tenckhoff catheter. There was also a slight reduction in other mechanical complications although the difference was not significant. Our failure to achieve significance may be due to the small number of patients in the series and the low incidence of complications.

The advantage of the Tenckhoff catheter became more obvious when we considered the number of patients who required a change of catheter or had a catheter removed due to complications. Our study showed that the likelihood of complications was 1.9 times greater with the Trocath than with the Tenckhoff catheter $(0 \cdot 19$ versus $0 \cdot 10$, respectively).
If we accept the increased number of mechanical problems with the Trocath catheter, however, and are prepared to replace it when indicated, patients can be dialysed effectively with either catheter, as shown by the similar outcome in our two groups. Although the Tenckhoff catheter led to fewer complications, it did not eliminate them, especially the life threatening problems such as peritonitis. Ironically the only catheter related death in our is series occurred in a patient dialysed with the Tenc- $\overrightarrow{0}$ khoff catheter.

We attempted to minimise errors due to selection bias by including in our study all available patients who met our preset criteria and by explicitly defining complications and the time period of the study to maintain consistency throughout. Nevertheless some complications may have been missed oo because not all charts were available for review and $N$ some complications may not have been docu- 의 mented. This may have led to inaccuracies in this study. Although the type of catheter inserted in $c$ some cases may have been influenced by the patient's clinical condition, such a decision would $\vec{\bullet}$ usually have placed the higher risk patients in the $\infty_{\infty}^{\infty}$ group receiving the Tenckhoff catheter in which there were fewer complications.

The present study supports our belief that the Tenckhoff catheter is better than the traditional Trocath catheter even for short term peritoneal $\stackrel{\infty}{\varnothing}$ dialysis. Our results are based on retrospective $\varrho$ uncontrolled data, however, and should be interpreted with appropriate caution.

We thank the Medical Publications Department, The Hospital for Sick Children, Toronto, for assistance in preparing this paper.

\section{References}

1 Swan $\mathrm{H}$, Gordon $\mathrm{HH}$. Peritoneal lavage in the treatment of anuria in children. Pediatrics 1949;4:586-95.

2 Segar WE, Gibson RK, Rhamy R. Peritoneal dialysis in infants and small children. Pediatrics 1961;27:603-13.

3 Etteldorf JN, Dobbins WT, Sweeney MJ, Smith JD, Whittington GL, Sheffield JA. Intermittent peritoneal dialysis in the management of acute renal failure in children. $J$ Pediatr 1962;60:327-39.

4 Chan JCM, Campbell RA. Peritoneal dialysis in children: a survey of its indications and applications. Clin Pediatr $\mathrm{N}$ 1973;12:131-9.

5 Donn SM, Swartz RD, Thoene JG. Comparison of exchange $\mathcal{\omega}$ transfusion, peritoneal dialysis, and hemodialysis for the treatment of hyperammonemia in an anuric newborn infant. $J$ Pediatr 1979;95:67-70.

6 Sallan SE, Cottom D. Peritoneal dialysis in maple syrup urine $\mathbb{D}$ disease. Lancet 1969;ii:1423-4.

7 Tenckhoff H, Schechter H. A bacteriologically safe peritoneal $\square$ access device. Trans Am Soc Artif Intern Organs 1968;14:181-7.

8 Fine RN. Peritoneal dialysis update. J Pediatr 1982;100:1-7.

9 Alexander SR. Peritoneal dialysis in children. In: Nolph KD, $\frac{\mathcal{\rho}}{\overparen{T}}$ ed. Peritoneal dialysis. 2nd ed. Boston: Martinus Nijhoff, Q 1985:525-60. 
10 Watson AR, Vigneux A, Hardy BE, Balfe J. Six-year experience with CAPD catheters in children. Peritoneal Dialysis Bulletin 1985;5:119-22.

11 Vaamonde CA, Michael UF, Metzger RA, Carroll KE. Complications of acute peritoneal dialysis. J Chronic Dis 1975;28: 637-59.

12 Valk TW, Swartz RD, Hsu CH. Peritoneal dialysis in acute renal failure: analysis of outcome and complications. Dialysis and Transplantation 1980;9:48-54.
13 Rigden SPA, Barratt TM, Dillon MJ, De Leval M, Stark J. Acute renal failure complicating cardiopulmonary bypass surgery. Arch Dis Child 1982;57:425-30.

Correspondence and requests for reprints to Dr Denis F Geary, Department of Paediatrics, Hospital for Sick Children, 555 University Avenue, Toronto. Ontario. Canada M5G 1X8.

Accepted 2 December 1987 